\title{
Prognostic value of decreased microRNA- I33a in solid cancers: a meta-analysis
}

This article was published in the following Dove Press journal:

OncoTargets and Therapy

21 September 2016

Number of times this article has been viewed

\section{Jian Xiao \\ Yong Zou \\ Xiaoxiao Lu \\ Bin Xie \\ Qiao Yu \\ Baimei He \\ Bixiu $\mathrm{He}$ \\ Qiong Chen}

Department of Geriatrics, Respiratory Medicine, Xiangya Hospital of Central South University, Changsha, People's Republic of China
Correspondence: Qiong Chen Department of Geriatrics, Respiratory Medicine, Xiangya Hospital of Central South University, 87 Xiangya Rd, Changsha 4I0008, Hunan Province, People's Republic of China

Tel+8673189753756

Email qiongch@।63.com
Objective: Increasing evidence indicates that the decreased expression of microRNA-133a (miR-133a) may be correlated with poor survival for cancer patients. Thus, we performed this meta-analysis to evaluate the prognostic value of decreased miR-133a in solid cancers.

Methods: Eligible studies were gathered by searching on PubMed, Web of Science, and Embase. Using the STATA 12.0 software, the pooled hazard ratios (HRs) and their corresponding 95\% confidence intervals (CIs) for total and subgroup analyses were calculated to investigate the possible correlation between decreased miR-133a and overall survival (OS) of patients with cancer.

Results: Ten studies were enrolled in this meta-analysis. The pooled result showed that decreased expression of miR-133a predicted poor OS in solid cancer patients (HR $=1.62$, 95\% CI: 1.16-2.24, $P=0.004)$. Compared with the total pooled HR, further analyses indicated that the subgroups of digestive system neoplasms ( $\mathrm{HR}=1.73,95 \% \mathrm{CI}: 1.20-2.51, P=0.003$ ), frozen tissue preservation ( $\mathrm{HR}=1.89,95 \% \mathrm{CI}: 1.41-2.53, P<0.001)$, and multivariate analysis ( $\mathrm{HR}=2.07,95 \% \mathrm{CI}: 1.42-3.02, P<0.001)$ exhibited stronger connection between decreased miR-133a expression and OS outcome.

Conclusion: This meta-analysis suggested that decreased miR-133a was associated with poor OS in patients with solid cancer. Because of the data in our study are limited, additional studies are required to verify the poor prognosis of decreased miR-133a in solid tumors.

Keywords: prognosis, microRNA-133a, solid cancers, meta-analysis

\section{Introduction}

Cancer is one of the most important health problems of mankind. The 5-year relative survival rate for all cancers in Americans and Chinese is $\sim 69 \%$ and $37 \%$, respectively. ${ }^{1,2}$ Thus, the researches for prognostic indicators of cancer survival have important clinical values. Nowadays, numerous cancer prognostic factors have been discovered, ${ }^{3-5}$ and the prognostic values of microRNAs also have been proved by many studies. ${ }^{6-8}$

MicroRNAs are a kind of small noncoding RNA molecule in biology, containing $\sim 22$ nucleotides, that function in posttranscriptional regulation of gene expression and RNA silencing. ${ }^{9,10}$ MicroRNAs regulate tumorigenesis and cancer progression, also as gatekeepers of apoptosis for tumors. ${ }^{11,12}$ Through different mechanisms, microRNA can perform the role of a tumor promoter ${ }^{13,14}$ or cancer suppressor factor. ${ }^{15-17}$ Meanwhile, microRNA in cancers can also be up- ${ }^{18,19}$ or downregulated. ${ }^{20,21}$

MicroRNA-133a (miR-133a) plays an important role in cancer development and progression. Studies showed that miR-133a is a tumor suppressor. ${ }^{22,23}$ Consequently, decreased expression of miR-133a in cancer patients correlates with poor survival and prognosis. ${ }^{24-27}$ However, the results from some studies find that lower expression of miR-133a functioned as a favorable outcome factor. ${ }^{28,29}$ Thus, as these 
results so far seem to be controversial, it is still not enough to draw a conclusion for the prognostic value of decreased miR-133a.

As a fact, most researches assessing the implications of miR-133a expression in cancer were limited by the small sample sizes. Therefore, we performed this meta-analysis and expected to handle the inconsistencies of previous studies.

\section{Materials and methods} Search strategy

The searches were performed by two reviewers (Jian Xiao and Yong Zou) independently. Articles were searched on PubMed, Web of Science, and Embase (updated to February 19, 2016) with language restriction of English. The search terms of keywords and their combination were as the following: "microRNA-133a OR mir-133a OR microRNA133a OR mir133a OR 133a” AND "survival OR prognosis OR prognostic" AND "cancer OR tumor OR tumour OR neoplasm OR neoplasma OR cancers OR tumors OR tumours OR neoplasms OR neoplasmas OR carcinoma OR carcinomas". A manual search for the references of relevant articles was also performed to find out other potential studies. Any differences were resolved by discussion.

\section{Inclusion and exclusion criteria}

Eligible studies for this meta-analysis met the following inclusion criteria: 1) evaluated the correlation between miR133a expression and overall survival (OS) of patients with any cancer types; 2) full-text was available; and 3) reported hazard ratios (HRs) with 95\% confidence intervals (CIs) or sufficient data to evaluate the HRs and 95\% CIs. The exclusion criteria were the following: 1) nonhuman researches, meta-analysis, and duplicated studies; 2) letters, case reports, comments, and meeting abstracts; and 3) neither reported HR and 95\% CI nor parameters (such as survival curve) to indirectly obtain them.

\section{Data extraction}

Two investigators (Jian Xiao and Xiaoxiao Lu) reviewed the eligible articles independently. Any disagreements were brought to a conclusion by discussion. Information is collected from the following items: first author; year of publication, region, type of cancer, stage, cases, sex, median age, follow-up, test method, tissue preservation, cutoff value, patients with follow-up, high/low expression cases of miR133a, outcome, analysis of variance, $\mathrm{HR}$, and 95\% CI as well as source of HR. No specific information represented unreported content of any items above. If both univariate and multivariate analyses of OS results were performed, HRs and 95\% CIs were extracted preferentially from the multivariate analyses. When Kaplan-Meier curves were the only available information, OS data were gained from the previously stated method. ${ }^{30}$

\section{Statistical analysis}

STATA 12.0 software (StataCorp LP, College Station, TX, USA) was used to conduct all the statistical analyses. According to the cutoff values provided by the original published articles, miR-133a was defined as a high (or upregulated) and low (or downregulated) group. The HRs and their corresponding 95\% CIs were performed to calculate the pooled HRs and 95\% CIs. If HR $>1$ and its 95\% CI did not overlap with 1 , patients with decreased expression of miR-133a indicated a poor prognosis. The heterogeneity of combined HRs was figured out using Cochran's $Q$ test and Higgins' $I$-squared statistic. If there was a result of $P<0.05$ or $I^{2}>50 \%$, heterogeneity was defined, and then the randomeffects model was applied. If not, a fixed-effects model was conducted. Subgroup analysis and meta-regression were further adopted to explore the possible explanations for heterogeneity. Sensitivity analysis, by successively omitting each study, was performed to assess the stability of the results. Publication bias was evaluated by Begg's and Egger's test. $P<0.05$ was considered statistically significant, and all the $P$-values were two-tailed.

\section{Results \\ Eligible studies and characteristics}

The initial search identified 59 potentially relevant records. After the duplicates were removed, 28 records were preserved. By further reviewing, 21 studies were determined to be of acceptable relevance and assessed for eligibility. However, eleven of them were excluded due to without OS data. Finally, ten studies met the eligible criteria and were included in this meta-analysis. ${ }^{24-29,31-34}$ The flow diagram on the selection process is shown in Figure 1.

In total, 877 patients with follow-up data from four regions (People's Republic of China, Iran, Japan, and Taiwan) were included in this study. Solid cancers included in our metaanalysis derived from five cancer types: osteosarcoma, ${ }^{24,28,33}$ non-small-cell lung cancer (NSCLC), ${ }^{26,34}$ esophageal cancer ${ }^{32}$ (or esophageal squamous cell carcinoma ${ }^{31}$ ), colorectal cancer, ${ }^{25,29}$ and pancreatic cancer. ${ }^{27}$ All of the miR-133a expression was tested by quantitative real-time polymerase chain reaction. The main characteristics of ten eligible studies are summarized in Tables 1 and 2 . 


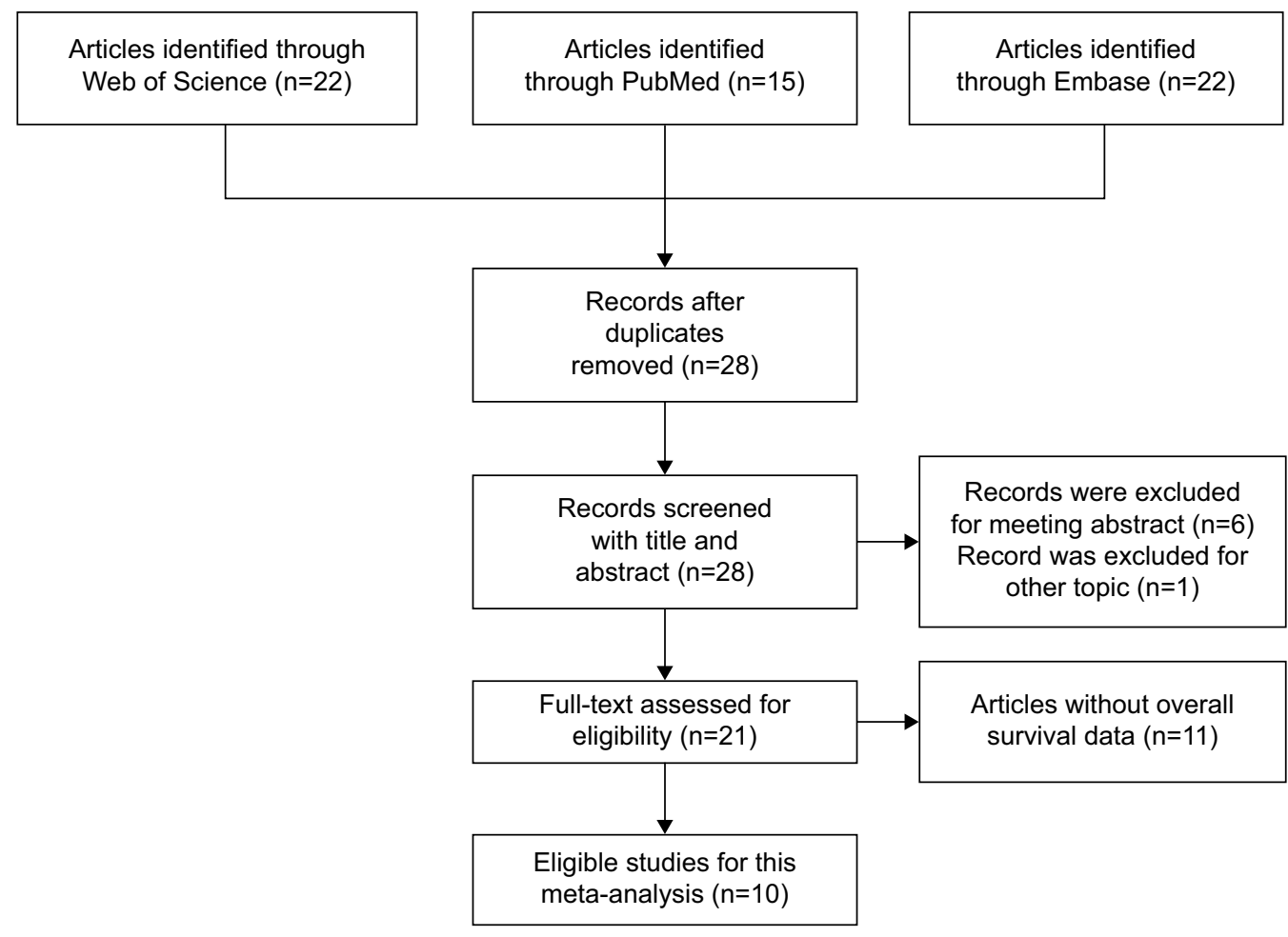

Figure I Flow diagram of the selection of eligible studies.

\section{OS is associated with decreased miR-I33a expression}

The pooled HR showed that decreased expression of miR133a was significantly associated with unfavorable OS in patients with solid cancers ( $\mathrm{HR}=1.62,95 \%$ CI: 1.16-2.24, $P=0.004$ ) (Figure 2). However, obvious heterogeneity $\left(I^{2}=59.3 \%, P=0.008\right)$ was discovered by using a randomeffects model. Therefore, sensitivity analysis was performed to assess the stability of the results by successively omitting each study. Results showed the pooled HRs did not vary substantially by excluding any individual study, indicating a better stability of this meta-analysis (Figure 3). Furthermore, a meta-regression was conducted to investigate the potential responsible factors for the heterogeneity. It found that none of these factors, including region, cancer type, cases (as well as the number of patients with follow-up data), maximum follow-up month, tissue preservation, cutoff value, and analysis of variance was contributing to the heterogeneity significance.

Subgroup analyses were performed according to the following categories: cancer type, region, tissue preservation, and analysis of variance. As the results shown in Figure 4

Table I Main characteristics of the eligible studies

\begin{tabular}{|c|c|c|c|c|c|c|c|c|}
\hline Study & Year & Region & Type of cancer & Stage & Cases & $\begin{array}{l}\text { Sex } \\
\text { (male/female) }\end{array}$ & $\begin{array}{l}\text { Median age } \\
\text { (range) }\end{array}$ & $\begin{array}{l}\text { Follow-up } \\
\text { (months) }\end{array}$ \\
\hline$\overline{\text { Ji et } \mathrm{al}^{33}}$ & 2013 & People's Republic of China & Osteosarcoma & I-III & 92 & $64 / 28$ & $20(7-73)$ & 60 \\
\hline Mirghasemi et $\mathrm{al}^{24}$ & 2015 & Iran & Osteosarcoma & I-IV & 35 & $18 / 17$ & NSI & 78 \\
\hline Lan et $\mathrm{al}^{34}$ & 2015 & People's Republic of China & NSCLC & I-IV & 125 & $75 / 50$ & $61.1(23-90)$ & 51 \\
\hline Fujiwara et $\mathrm{al}^{28}$ & 2014 & Japan & Osteosarcoma & NSI & 48 & $31 / 17$ & NSI & 143 \\
\hline Chen et $\mathrm{a}^{31}$ & 2014 & People's Republic of China & ESCC & I-IV & 100 & $69 / 31$ & $50(40-80)$ & 50 \\
\hline Akanuma et a $\mathrm{a}^{32}$ & 2014 & Japan & Esophageal cancer & I-IV & 140 & $121 / 19$ & NSI & 120 \\
\hline Wan et $\mathrm{al}^{29}$ & 2014 & People's Republic of China & Colorectal cancer & I-IV & 125 & $73 / 51$ & $71.8(29-95)$ & 65 \\
\hline Wang et $\mathrm{a}^{26}$ & 2014 & Taiwan & NSCLC & I-III & 112 & $88 / 24$ & NSI & 52 \\
\hline Qin et $\mathrm{al}^{27}$ & 2013 & People's Republic of China & Pancreatic cancer & $\mid-I I$ & 95 & $40 / 55$ & NSI & 58 \\
\hline Wang et $\mathrm{a}^{25}$ & 2014 & People's Republic of China & Colorectal cancer & I-III & 169 & $96 / 73$ & NSI & 77 \\
\hline
\end{tabular}

Abbreviations: ESCC, esophageal squamous cell carcinoma; NSI, no specific information; NSCLC, non-small-cell lung cancer. 


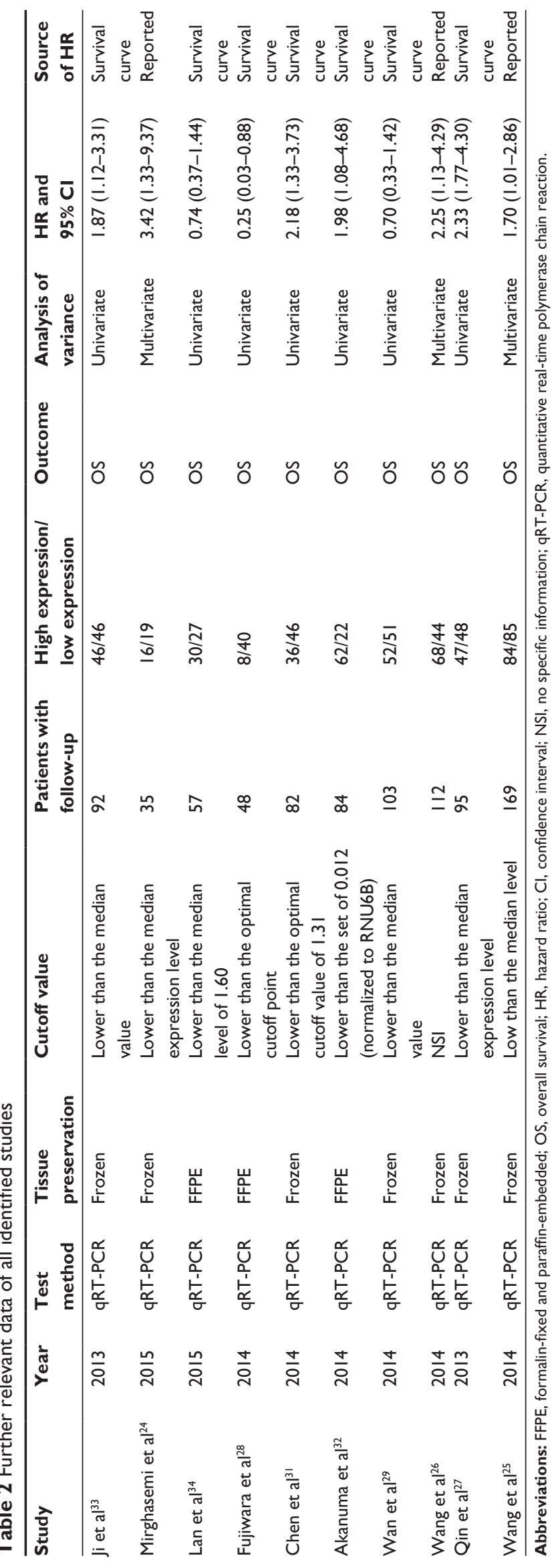

and Table 3, compared with the total pooled HR, decreased miR-133a exhibited a stronger correlation with poor OS in the subgroups of digestive system neoplasms ( $\mathrm{HR}=1.73$, 95\% CI: $1.20-2.51, P=0.003)$, frozen tissue preservation ( HR $=1.89,95 \%$ CI: $1.41-2.53, P<0.001)$, and multivariate analysis (HR $=2.07,95 \% \mathrm{CI}: 1.42-3.02, P<0.001)$. In the meantime, these three subgroups also presented relatively low heterogeneity $\left(I^{2}=52.2 \%, P=0.079 ; I^{2}=40.5 \%, P=0.121\right.$; and $I^{2}=0.0 \%, P=0.443$, respectively) (Table 3 ). However, subgroups, such as osteosarcoma, NSCLC, formalin-fixed and paraffin-embedded (FFPE) tissue preservation, and univariate analysis, showed no statistically significant association between decreased miR-133a and OS outcome (Table 3).

\section{Publication bias assessment}

As shown in Figure 5, we performed Begg's funnel plot and Egger's test to evaluate the publication bias for all articles in this meta-analysis. The $P$-values of Begg's and Egger's test were 0.37 and 0.15 , respectively, suggesting no obvious risk of publication bias.

\section{Discussion}

In mammal cells, miR-133a performs many regulating functions. It regulates adipocyte browning in $\mathrm{vivo}^{35}$ and modulates osteogenic differentiation of the vascular smooth muscle cells. ${ }^{36} \mathrm{MiR}-133 \mathrm{a}$ is also a biomarker for postmenopausal osteoporosis ${ }^{37}$ and can predict cardiac hypertrophy in chronic hemodialysis patients. ${ }^{38}$ In cancer research, miR-133a is regarded as a potential biomarker for breast cancer detection. ${ }^{39}$ It inhibits the growth of cervical cancer and gastric cancer by targeting epidermal growth factor receptor and insulin-like growth factor-1 receptor, respectively. ${ }^{40,41}$ Therefore, miR-133a is considered to be a tumor suppressor. Consequently, downregulated miR-133a induces cancer progression and predicts poor prognosis in cancer patients. ${ }^{24,25}$ However, no meta-analyses are performed so far to evaluate the prognostic value of decreased miR-133a in patients with solid cancers. So, we have done this meta-analysis.

In our meta-analysis, ten eligible articles met the inclusion criteria. The outcome of cancer patients was collected by OS data. By using a random-effects model to get the pooled HRs, the combined results indicated that decreased miR-133a expression was associated with an unfavorable prognosis in patients with solid cancers. Sensitivity analysis showed that no individual study was obviously affecting the overall result, indicating the pooled result of this meta-analysis is stable. However, due to evident heterogeneity between the 


\begin{tabular}{|c|c|c|c|}
\hline Study ID & & HR (95\% Cl) & Weight (\%) \\
\hline Ji et $a^{33}(2013)$ & $\longrightarrow$ & $1.87(1.12-3.31)$ & 12.08 \\
\hline Mirghasemi et al ${ }^{24}$ (2015) & & $3.42(1.33-9.37)$ & 6.92 \\
\hline Lan et $\mathrm{al}^{34}(2015)$ & & $0.74(0.37-1.44)$ & 10.15 \\
\hline Fujiwara et $\mathrm{al}^{28}(2014) \leftarrow$ & & $0.25(0.03-0.88)$ & 3.10 \\
\hline Chen et al ${ }^{31}(2014)$ & & $2.18(1.33-3.73)$ & 12.47 \\
\hline Akanuma et al ${ }^{32}$ (2014) & & $1.98(1.08-4.68)$ & 9.47 \\
\hline Wan et $\mathrm{al}^{29}(2014)$ & - : & $0.70(0.33-1.42)$ & 9.51 \\
\hline Wang et $\mathrm{al}^{26}(2014)$ & & $2.25(1.13-4.29)$ & 10.32 \\
\hline Qin et $\mathrm{al}^{27}(2013)$ & & $2.33(1.77-4.30)$ & 13.57 \\
\hline Wang et $\mathrm{al}^{25}(2014)$ & & $1.70(1.01-2.86)$ & 12.40 \\
\hline Overall $\left(I^{2}=59.3 \%, P=0.008\right)$ & & $1.62(1.16-2.24)$ & 100 \\
\hline 0.03 & 1 & 33.3 & \\
\hline
\end{tabular}

Figure 2 Forest plot showing the association between decreased microRNA-I33a and OS in patients with solid cancers (used a random-effects model). Note: Weights are from random-effects analysis.

Abbreviations: $\mathrm{Cl}$, confidence interval; $\mathrm{HR}$, hazard ratio; OS, overall survival.

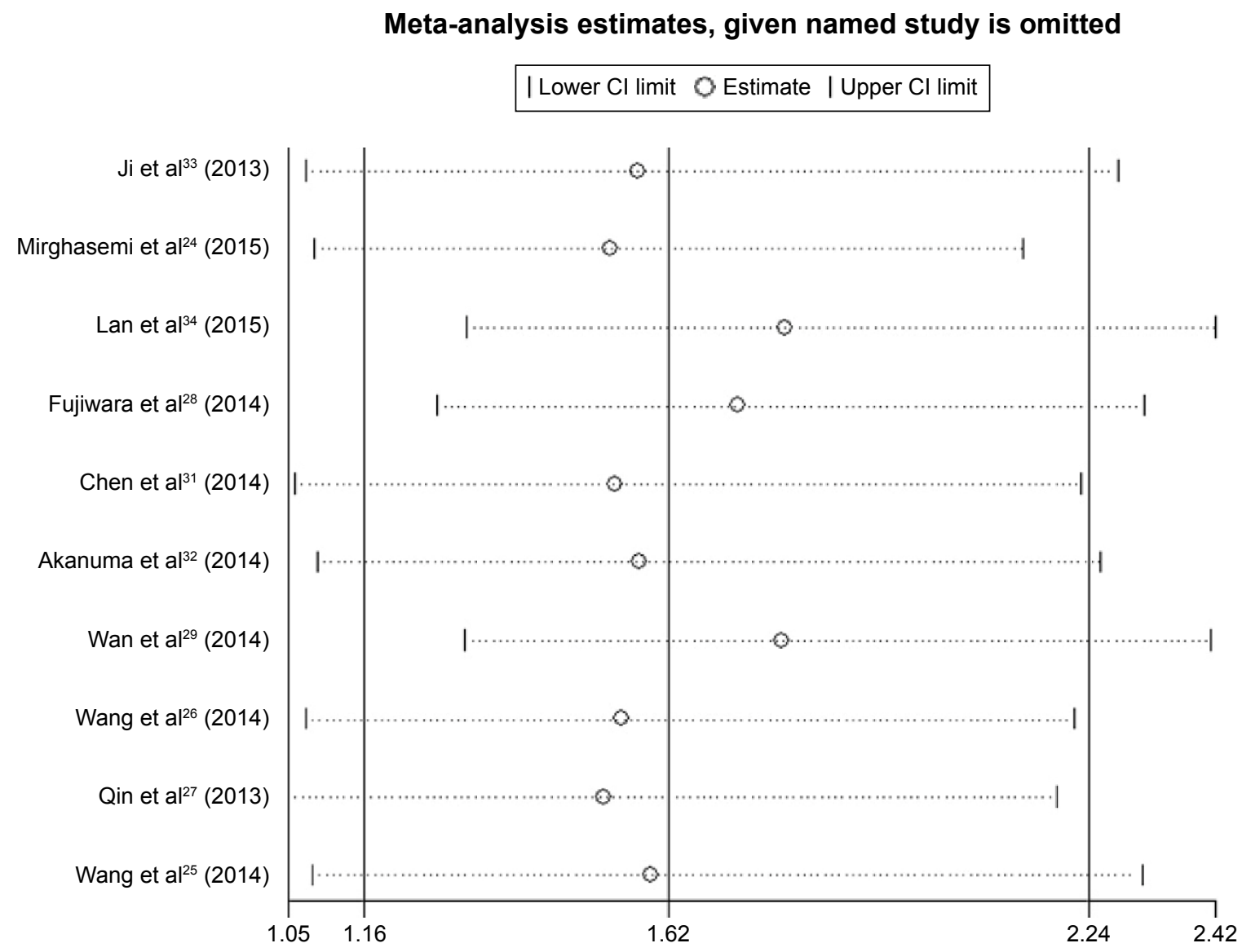

Figure 3 Sensitivity analysis for this meta-analysis. Abbreviation: $\mathrm{Cl}$, confidence interval. 


\begin{tabular}{|c|c|c|c|}
\hline \multicolumn{2}{|l|}{ Study ID } & \multirow[t]{2}{*}{$\mathrm{HR}(95 \% \mathrm{Cl})$} & Weight (\%) \\
\hline Osteosarcoma & & & \\
\hline Ji et $a^{33}(2013)$ & $\longrightarrow$ & $1.87(1.12-3.31)$ & 43.47 \\
\hline Mirghasemi et al ${ }^{24}(2015)$ & $\rightarrow$ & $3.42(1.33-9.37)$ & 34.66 \\
\hline Fujiwara et $\mathrm{al}^{28}(2014) \leftarrow$ & & $0.25(0.03-0.88)$ & 21.87 \\
\hline Subtotal $\left(I^{2}=71.1 \%, P=0.032\right)$ & & $1.48(0.51-4.29)$ & 100 \\
\hline \multicolumn{4}{|l|}{ Non-small cell lung cancer } \\
\hline Lan et $\mathrm{al}^{34}(2015)$ & & $0.74(0.37-1.44)$ & 49.82 \\
\hline Wang et $\mathrm{al}^{26}(2014)$ & & $2.25(1.13-4.29)$ & 50.18 \\
\hline Subtotal $\left(I^{2}=80.9 \%, P=0.022\right)$ & & $1.29(0.43-3.84)$ & 100 \\
\hline \multicolumn{4}{|l|}{ Digestive system neoplasms } \\
\hline Chen et $\mathrm{al}^{31}(2014)$ & & $2.18(1.33-3.73)$ & 22.18 \\
\hline 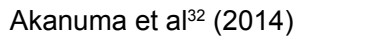 & & $1.98(1.08-4.68)$ & 15.37 \\
\hline Wan et $\mathrm{al}^{29}(2014)$ & & $0.70(0.33-1.42)$ & 15.46 \\
\hline Qin et $\mathrm{al}^{27}(2013)$ & - & $2.33(1.77-4.30)$ & 24.98 \\
\hline Wang et $\mathrm{al}^{25}(2014)$ & & $1.70(1.01-2.86)$ & 22.00 \\
\hline Subtotal $\left(I^{2}=52.2 \%, P=0.079\right)$ & & $1.73(1.20-2.51)$ & 100 \\
\hline 0.03 & 1 & $\begin{array}{c}1 \\
33.3\end{array}$ & \\
\hline
\end{tabular}

Figure 4 Forest plots showing the HRs and their corresponding Cls by cancer type subgroups (used a random-effects model).

Note: Weights are from random-effects analysis.

Abbreviations: $\mathrm{Cl}$, confidence interval; $\mathrm{HR}$, hazard ratio.

included studies, we conducted further subgroup analyses regarding cancer type, region, tissue preservation, and analysis of variance. Despite osteosarcoma, NSCLC, FFPE tissue preservation, and univariate analysis subgroups showed no statistically significant correlation between decreased miR133a and OS. While, compared with the total pooled HR, the subgroups of digestive system neoplasms, frozen tissue preservation, and multivariate analysis exhibited stronger connection between decreased miR-133a expression and OS outcome with relatively low heterogeneity. In addition, no publication bias was observed.

The results of this meta-analysis have several considerable implications. First, decreased miR-133a may be a common poor prognostic marker for solid cancers. The original researches of our meta-analysis were derived from five cancer types: osteosarcoma, ${ }^{24,28,33}$ NSCLC, ${ }^{26,34}$ esophageal cancer, ${ }^{31,32}$ colorectal cancer, ${ }^{25,29}$ and pancreatic cancer. ${ }^{27}$ As the pooled result from all these cancer types showed decreased

Table 3 Main results of subgroup analyses

\begin{tabular}{|c|c|c|c|c|c|c|}
\hline \multirow[t]{2}{*}{ Categories } & \multirow[t]{2}{*}{ Subgroups } & \multirow[t]{2}{*}{ References } & \multirow[t]{2}{*}{ HR (95\% Cl) } & \multirow[t]{2}{*}{$P$-value } & \multicolumn{2}{|c|}{ Heterogeneity } \\
\hline & & & & & $I^{2}(\%)$ & $P$-value \\
\hline All & Total & $24-29,31-34$ & $1.62(1.16-2.24)$ & 0.004 & 59.3 & 0.008 \\
\hline \multirow[t]{3}{*}{ Cancer type } & Osteosarcoma & $24,28,33$ & I.48 (0.5I-4.29) & 0.466 & 71.1 & 0.032 \\
\hline & Non-small-cell lung cancer & 26,34 & $1.29(0.43-3.84)$ & 0.644 & 80.9 & 0.022 \\
\hline & Digestive system neoplasms & $25,27,29,31,32$ & $\mathrm{I} .73(\mathrm{I} .20-2.5 \mathrm{I})$ & 0.003 & 52.2 & 0.079 \\
\hline \multirow[t]{2}{*}{ Region } & East Asia & $25-29,31-34$ & $1.53(1.09-2.14)$ & 0.013 & 60.3 & 0.010 \\
\hline & West Asia & 24 & $3.42(1.29-9.08)$ & 0.014 & - & - \\
\hline Tissue & Frozen & $24-27,29,31,33$ & $\mathrm{I} .89(\mathrm{I} .4 \mathrm{I}-2.53)$ & $<0.001$ & 40.5 & 0.121 \\
\hline preservation & FFPE & $28,32,34$ & $0.88(0.33-2.32)$ & 0.791 & 70.0 & 0.036 \\
\hline Analysis & Univariate & $27-29,31-34$ & $1.38(0.88-2.15)$ & 0.156 & 68.9 & 0.004 \\
\hline of variance & Multivariate & $24-26$ & $2.07(1.42-3.02)$ & $<0.001$ & 0.0 & 0.443 \\
\hline
\end{tabular}

Note: “-” indicates no data.

Abbreviations: $\mathrm{HR}$, hazard ratio; $\mathrm{Cl}$, confidence interval; FFPE, formalin-fixed and paraffin-embedded. 
A

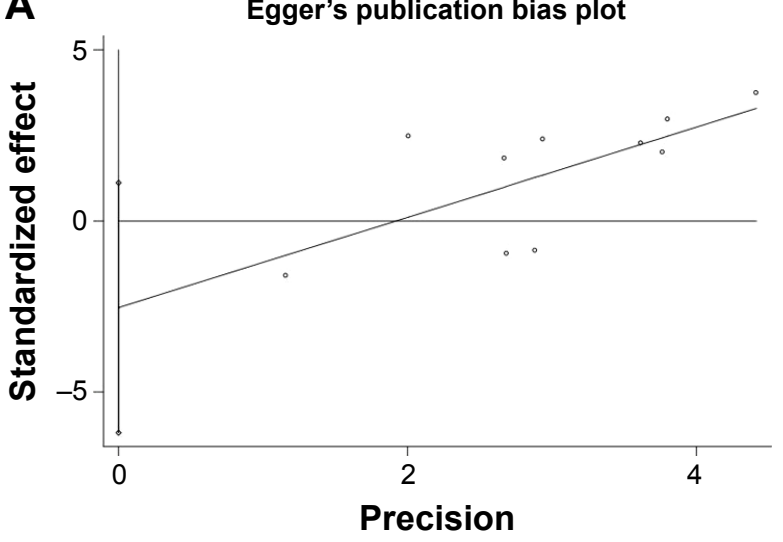

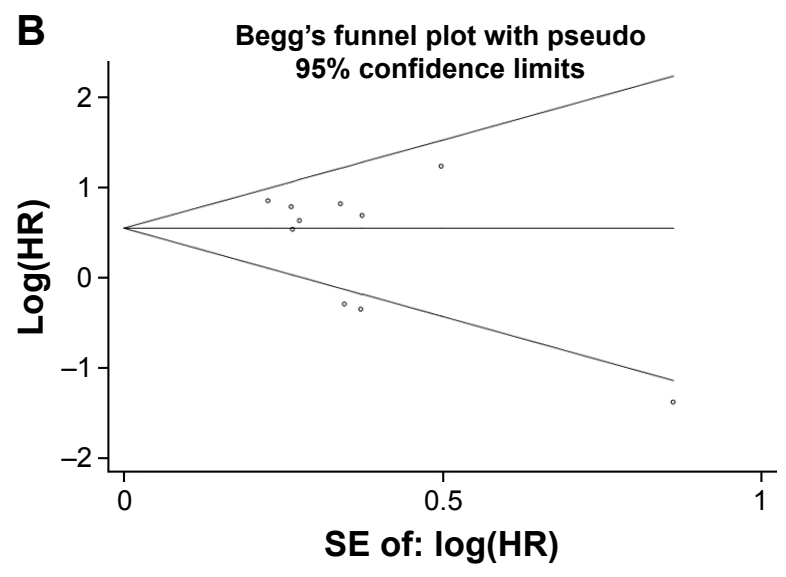

Figure 5 Egger's plot (A) and Begg's funnel plot (B) for publication bias. Abbreviation: SE, standard error.

miR-133a was correlated with a poor OS; thus, the conclusion can basically extend to all solid cancers. ${ }^{42,43}$ Second, decreased miR-133a probably is a reliable biomarker of poor survival for patients with digestive system neoplasms. Our analysis results showed that decreased miR-133a in patients with digestive system neoplasms exhibited poorer OS compared with osteosarcoma and NSCLC. However, the specific mechanism for this phenomenon needs to be explored in further research. Third, cancer tissues preserved by freezing may be more appropriate for microRNA detection than FFPE. Although studies showed consistent correlations between matched FFPE and frozen samples on the expression of microRNAs, ${ }^{44,45}$ the expression of a specific microRNA (eg, miR-133a) maybe is different. Unlike FFPF tissue preservation subgroup, our results indicated decreased miR-133a was obviously associated with poor prognosis in frozen tissues. It implicated that frozen tissues may reflect the expression of microRNA more actually than FFPE samples. Fourth, multivariate analysis maybe is more suitable for the researches on the correlation between microRNA expression and OS outcome in patients with cancer. The multivariate analysis subgroup in this meta-analysis exhibited stronger connection between decreased miR-133a expression and OS compared with the subgroup of univariate analysis. However, as the multivariate analysis ruled out the compounding effects from other factors, such as tumor size, stage, and nodal status, ${ }^{24-26}$ the pooled results from studies conducted by multivariate analysis may be considered as more reliable.

In cancer, microRNAs act as tumor suppressors when they downregulate different proteins with oncogenic activity. ${ }^{46}$ Similarly, microRNAs act as oncogenes if they downregulate genes involved in cell differentiation or as tumor suppressors. ${ }^{46}$ For the ten original studies included in our meta-analysis, most of them reported that miR-133a functions as a tumor suppressor and the decreased expression of miR-133a was correlated with poor prognostic in patients with solid cancer while a few other studies reported inconsistent results, ${ }^{28,29,34}$ indicating miR-133a maybe is a tumor promoter. We considered the reason for this paradox maybe is that miR-133a downregulated different target genes in different cancer types (Table 4).

Except for miR-133a, the miR-133 family also contains miR-133b. Studies found that miR-133b acts as a tumor suppressor and its expression was decreased in many types of solid cancers, such as NSCLC, bladder cancer, ovarian cancer, and gastric cancer. ${ }^{47-50}$ In addition, many other

Table 4 The validated target genes of miR-133a in the eligible studies in this meta-analysis

\begin{tabular}{llll}
\hline Study & Year & Type of cancer & Validated target genes \\
\hline Ji et al ${ }^{33}$ & 2013 & Osteosarcoma & Bcl-xL and Mcl-I \\
Fujiwara et al ${ }^{28}$ & 2014 & Osteosarcoma & SGMS2, UBA2, SNX30, and ANXA2 \\
Akanuma et al ${ }^{32}$ & 2014 & Esophageal cancer & FSCNI and MMPI4 \\
Wan et al ${ }^{29}$ & 2014 & Colorectal cancer & LASPI, CAVI, and FSCNI \\
Wang et al $^{26}$ & 2014 & Non-small-cell lung cancer & IGF-IR, TGFBRI, and EGFR \\
Qin et al ${ }^{27}$ & 2013 & Pancreatic cancer & FSCNI \\
\hline
\end{tabular}

Abbreviations: ANXA2, annexin A2; Bcl-xL, B-cell lymphoma-extra large; CAVI, caveolin-I; EGFR, epidermal growth factor receptor; FSCNI, Fascin-I; IGF-IR, insulin-like growth factor I receptor; LASPI, LIM and SH3 domain protein I; MMPI4, matrix metalloprotease I4; Mcl-I, myeloid cell leukemia-I; SGMS2, sphingomyelin synthase 2; SNX30, sorting nexin family member 30; TGFBRI, TGF-beta receptor type-I; UBA2, ubiquitin-like modifier activating enzyme 2. 
studies also reported that both miR-133a and miR-133b were decreased together in solid cancer tissues. ${ }^{31,50-52}$ Further considering the results of our current meta-analysis, all these evidences indicate that the decreased expression of miR-133 family maybe is the reliable predictor, suggesting patients with solid cancer will have a poor prognosis.

Nevertheless, when interpreting the results of this metaanalysis, several limitations should be noticed. One of the main limitations is the limited region for the included source of cancer patients. Patient populations in this study were limited to Asia, lacking data from other regions, such as Europe, America, Oceania, and Africa. Our results need to be proved by more studies from other regions. Another limitation is that some HR data were extracted from survival curves, which may introduce bias. Thus, the present statistics seem to be less reliable than those directly obtained from published studies. If possible, pooled HRs should be performed based on directly obtained data from the published studies. In addition, all of the included studies in our meta-analysis were designed for retrospective studies, which are more possible to be published when they report positive rather than negative results. Consequently, the association between decreased miR-133a and poor OS may have been overestimated. Finally, obvious heterogeneity showed in between studies, even though we used random-effects models to calculate the pooled HRs. The heterogeneity may be attributed to the inconformity in different population characteristics, types of cancer, treatment strategies, and so on, which will likely reduce the reliability of this study and those findings similar to ours. ${ }^{53,54}$

\section{Conclusion}

Our meta-analysis concluded that decreased miR-133a expression is significantly associated with poor OS in patients with solid cancer. However, our results also need to be cautiously considered because of the limitations described above. Further studies related to specific cancer types and large sample sizes are required to verify the prognostic value of decreased miR-133a in various cancers.

\section{Acknowledgment}

This work was funded by the National Natural Science Foundation of China (81572284).

\section{Disclosure}

The authors report no conflicts of interest in this work.

\section{References}

1. Siegel RL, Miller KD, Jemal A. Cancer statistics, 2016. CA Cancer J Clin. 2016;66(1):7-30.

2. Chen W, Zheng R, Baade PD, et al. Cancer statistics in China, 2015. CA Cancer J Clin. 2016;66(2):115-132.
3. Koutras A, Kotoula V, Fountzilas G. Prognostic and predictive role of vascular endothelial growth factor polymorphisms in breast cancer. Pharmacogenomics. 2015;16(1):79-94.

4. Aaltonen KE, Rosendahl AH, Olsson H, Malmstrom P, Hartman L, Ferno M. Association between insulin-like growth factor-1 receptor (IGF1R) negativity and poor prognosis in a cohort of women with primary breast cancer. BMC Cancer. 2014;14:794.

5. Leclerc BG, Charlebois R, Chouinard G, et al. CD73 Expression is an independent prognostic factor in prostate cancer. Clin Cancer Res. 2016;22(1):158-166.

6. Elhanati S, Ben-Hamo R, Kanfi Y, et al. Reciprocal Regulation between SIRT6 and miR-122 controls liver metabolism and predicts hepatocarcinoma prognosis. Cell Rep. 2016;14(2):234-242.

7. Hur K, Toiyama Y, Okugawa Y, et al. Circulating microRNA-203 predicts prognosis and metastasis in human colorectal cancer. Gut. Epub 2015 Dec 23.

8. Wang $\mathrm{W}$, Wang $\mathrm{X}$, Zhang Y, et al. Prognostic role of microRNA-150 in various carcinomas: a meta-analysis. Onco Targets Ther. 2016;9: 1371-1379.

9. Bartel DP. MicroRNAs: genomics, biogenesis, mechanism, and function. Cell. 2004;116(2):281-297.

10. Ambros V. The functions of animal microRNAs. Nature. 2004;431(7006): 350-355.

11. Nana-Sinkam SP, Croce CM. MicroRNA regulation of tumorigenesis, cancer progression and interpatient heterogeneity: towards clinical use. Genome Biol. 2014;15(9):445.

12. Subramanian S, Steer CJ. MicroRNAs as gatekeepers of apoptosis. J Cell Physiol. 2010;223(2):289-298.

13. Zhang L, Sun ZJ, Bian Y, Kulkarni AB. MicroRNA-135b acts as a tumor promoter by targeting the hypoxia-inducible factor pathway in genetically defined mouse model of head and neck squamous cell carcinoma. Cancer Lett. 2013;331(2):230-238.

14. Zou CD, Zhao WM, Wang XN, et al. MicroRNA-107: a novel promoter of tumor progression that targets the CPEB3/EGFR axis in human hepatocellular carcinoma. Oncotarget. 2016;7(1):266-278.

15. Chen S, Sun KX, Liu BL, Zong ZH, Zhao Y. MicroRNA-505 functions as a tumor suppressor in endometrial cancer by targeting TGF-alpha. Mol Cancer. 2016;15(1):11.

16. Shi ZC, Chu XR, Wu YG, et al. MicroRNA-375 functions as a tumor suppressor in osteosarcoma by targeting PIK3CA. Tumour Biol. 2015; 36(11):8579-8584.

17. Jin Y, Zhao M, Xie Q, Zhang H, Wang Q, Ma Q. MicroRNA-338-3p functions as tumor suppressor in breast cancer by targeting SOX4. Int $J$ Oncol. 2015;47(4):1594-1602.

18. Knudsen KN, Nielsen BS, Lindebjerg J, Hansen TF, Holst R, Sorensen FB. microRNA-17 Is the Most Up-Regulated Member of the miR-17-92 Cluster during Early Colon Cancer Evolution. PLoS One. 2015;10(10): e0140503.

19. He XJ, Ma YY, Yu S, et al. Up-regulated miR-199a-5p in gastric cancer functions as an oncogene and targets klotho. BMC Cancer. 2014;14: 218.

20. Zhu ED, Li N, Li BS, et al. miR-30b, down-regulated in gastric cancer, promotes apoptosis and suppresses tumor growth by targeting plasminogen activator inhibitor-1. PLoS One. 2014;9(8):e106049.

21. Jiang X, Huang H, Li Z, et al. MiR-495 is a tumor-suppressor microRNA down-regulated in MLL-rearranged leukemia. Proc Natl Acad Sci U S A. 2012;109(47):19397-19402.

22. Kojima S, Chiyomaru T, Kawakami K, et al. Tumour suppressors miR-1 and miR-133a target the oncogenic function of purine nucleoside phosphorylase (PNP) in prostate cancer. Br J Cancer. 2012;106(2): 405-413.

23. Zhang W, Liu K, Liu S, Ji B, Wang Y, Liu Y. MicroRNA-133a functions as a tumor suppressor by targeting IGF-1R in hepatocellular carcinoma. Tumour Biol. 2015;36(12):9779-9788.

24. Mirghasemi A, Taheriazam A, Karbasy SH, et al. Down-regulation of miR-133a and miR-539 are associated with unfavorable prognosis in patients suffering from osteosarcoma. Cancer Cell Int. 2015;15:86. 
25. Wang LL, Du LT, Li J, et al. Decreased expression of miR-133a correlates with poor prognosis in colorectal cancer patients. World $J$ Gastroenterol. 2014;20(32):11340-11346.

26. Wang LK, Hsiao TH, Hong TM, et al. MicroRNA-133a suppresses multiple oncogenic membrane receptors and cell invasion in non-small cell lung carcinoma. PLoS One. 2014;9(5):e96765.

27. Qin Y, Dang X, Li W, Ma Q. miR-133a functions as a tumor suppressor and directly targets FSCN1 in pancreatic cancer. Oncol Res. 2013;21(6):353-363.

28. Fujiwara T, Katsuda T, Hagiwara $K$, et al. Clinical relevance and therapeutic significance of microRNA-133a expression profiles and functions in malignant osteosarcoma-initiating cells. Stem Cells. 2014;32(4):959-973.

29. Wan TM, Lam CS, Ng L, et al. The clinicopathological significance of miR-133a in colorectal cancer. Dis Markers. 2014;2014:919283.

30. Krieg A, Riemer JC, Telan LA, Gabbert HE, Knoefel WT. CXCR4 A prognostic and clinicopathological biomarker for pancreatic ductal adenocarcinoma: a meta-analysis. PLoS One. 2015;10(6):e0130192.

31. Chen G, Peng J, Zhu W, et al. Combined downregulation of microRNA133a and microRNA-133b predicts chemosensitivity of patients with esophageal squamous cell carcinoma undergoing paclitaxel-based chemotherapy. Med Oncol. 2014;31(11):263.

32. Akanuma N, Hoshino I, Akutsu Y, et al. MicroRNA-133a regulates the mRNAs of two invadopodia-related proteins, FSCN1 and MMP14, in esophageal cancer. Br J Cancer. 2014;110(1):189-198.

33. Ji F, Zhang H, Wang Y, et al. MicroRNA-133a, downregulated in osteosarcoma, suppresses proliferation and promotes apoptosis by targeting Bcl-xL and Mcl-1. Bone. 2013;56(1):220-226.

34. Lan D, Zhang X, He R, et al. MiR-133a is downregulated in nonsmall cell lung cancer: a study of clinical significance. Eur J Med Res. 2015;20:50.

35. Liu W, Bi P, Shan T, et al. miR-133a regulates adipocyte browning in vivo. PLoS Genet. 2013;9(7):e1003626.

36. Liao XB, Zhang ZY, Yuan K, et al. MiR-133a modulates osteogenic differentiation of vascular smooth muscle cells. Endocrinology. 2013;154(9):3344-3352.

37. Wang Y, Li L, Moore BT, et al. MiR-133a in human circulating monocytes: a potential biomarker associated with postmenopausal osteoporosis. PLoS One. 2012;7(4):e34641.

38. Wen P, Song D, Ye H, et al. Circulating MiR-133a as a biomarker predicts cardiac hypertrophy in chronic hemodialysis patients. PLoS One. 2014;9(10):e103079.

39. Shen J, Hu Q, Schrauder M, et al. Circulating miR-148b and miR-133a as biomarkers for breast cancer detection. Oncotarget. 2014;5(14):5284-5294.

40. Song X, Shi B, Huang K, Zhang W. miR-133a inhibits cervical cancer growth by targeting EGFR. Oncol Rep. 2015;34(3):1573-1580.
41. Gong Y, Ren J, Liu K, Tang LM. Tumor suppressor role of miR$133 \mathrm{a}$ in gastric cancer by repressing IGF1R. World J Gastroenterol. 2015;21(10):2949-2958.

42. Dai SL, Zhou J, Pan C, et al. Prognostic value of microRNA-145 in patients with various cancers: a meta-analysis. Cancer Biomark. 2015; 15(4):507-513.

43. Wang F, Zhong S, Zhang H, et al. Prognostic value of microRNA-182 in cancers: a meta-analysis. Dis Markers. 2015;2015:482146.

44. Zhang X, Chen J, Radcliffe T, Lebrun DP, Tron VA, Feilotter H. An array-based analysis of microRNA expression comparing matched frozen and formalin-fixed paraffin-embedded human tissue samples. J Mol Diagn. 2008;10(6):513-519.

45. Meng W, McElroy JP, Volinia S, et al. Comparison of microRNA deep sequencing of matched formalin-fixed paraffin-embedded and fresh frozen cancer tissues. PLoS One. 2013;8(5):e64393.

46. Shenouda SK, Alahari SK. MicroRNA function in cancer: oncogene or a tumor suppressor? Cancer Metastasis Rev. 2009;28(3-4):369-378.

47. Chen SW, Wang TB, Tian YH, Zheng YG. Down-regulation of microRNA-126 and microRNA-133b acts as novel predictor biomarkers in progression and metastasis of non small cell lung cancer. Int J Clin Exp Pathol. 2015;8(11):14983-14988.

48. Chen XN, Wang KF, Xu ZQ, et al. MiR-133b regulates bladder cancer cell proliferation and apoptosis by targeting Bcl-w and Akt1. Cancer Cell Int. 2014;14:70.

49. Liu X, Li G. MicroRNA-133b inhibits proliferation and invasion of ovarian cancer cells through Akt and Erk1/2 inactivation by targeting epidermal growth factor receptor. Int J Clin Exp Pathol. 2015;8(9):10605-10614.

50. Liu Y, Zhang X, Zhang Y, et al. Identification of miRNomes in human stomach and gastric carcinoma reveals miR-133b/a-3p as therapeutic target for gastric cancer. Cancer Lett. 2015;369(1):58-66.

51. Kano M, Seki N, Kikkawa N, et al. miR-145, miR-133a and miR-133b: Tumor-suppressive miRNAs target FSCN1 in esophageal squamous cell carcinoma. Int J Cancer. 2010;127(12):2804-2814.

52. Qiu T, Zhou X, Wang J, et al. MiR-145, miR-133a and miR-133b inhibit proliferation, migration, invasion and cell cycle progression via targeting transcription factor Sp1 in gastric cancer. FEBS Lett. 2014; 588(7):1168-1177.

53. Qu J, Li M, Zhong W, Hu C. Prognostic role of microRNA-25 in cancers: evidence from a meta-analysis. Int J Clin Exp Med. 2015;8(8): 12921-12927.

54. Wang S, Hu J, Zhang D, Li J, Fei Q, Sun Y. Prognostic role of microRNA-31 in various cancers: a meta-analysis. Tumour Biol. 2014; 35(11):11639-11645.
OncoTargets and Therapy

\section{Publish your work in this journal}

OncoTargets and Therapy is an international, peer-reviewed, open access journal focusing on the pathological basis of all cancers, potential targets for therapy and treatment protocols employed to improve the management of cancer patients. The journal also focuses on the impact of management programs and new therapeutic agents and protocols on

\section{Dovepress}

patient perspectives such as quality of life, adherence and satisfaction. The manuscript management system is completely online and includes a very quick and fair peer-review system, which is all easy to use. Visit http://www.dovepress.com/testimonials.php to read real quotes from published authors. 